\title{
The Relationship between Serum Leptin and Blood Pressure in Obese and Non Obese Male Subjects
}

\author{
Hassan M. Eissa ${ }^{1}$, Sahar M. Kamal ${ }^{1,}$ Tarek M. Ali ${ }^{2}$, and Ahmed A $T^{2}$ \\ ${ }^{1}$ Department of physiology, Faculty of Medicine, Cairo University, Egypt \\ ${ }^{2}$ Department of physiology, Faculty of Medicine, Beni-Suef University, Egypt \\ *Correspondence author: e- mail: tarek70ali@gmail.com
}

\begin{abstract}
Objectives: To clarify the relationship between serum leptin level and arterial blood pressure (ABP) and lipid profile in obese and non-obese male subjects. Methods: The present study was performed in Beni Suef University, Faculty of medicine between December 2007 and December 2008. Fasting serum leptin level, arterial blood pressure, lipid profile, waist circumference (WC) and body mass index (BMI) were measured in 10 lean normotensive (LN), 10 obese normotensive $(\mathrm{ON}), 10$ lean hypertensive (LH) and 10 obese hypertensive males $(\mathrm{OH})$. Results: In the present study, serum leptin, BMI, and WC were significantly elevated in obese subjects than in lean subjects whether normotensive or hypertensive $(P<0.001)$. In lean groups, serum leptin level was significantly higher in hypertensive than in normotensive persons $(P<0.001)$. In all studied subjects, mean $A B P$ was significantly related to serum leptin. In obese groups, and in lean groups, serum leptin was positively correlated with mean $A B P$ and all measured lipid profile parameters except high density lipoprotein (HDL) to which it was negatively correlated. Serum leptin was positively correlated with WC in obese normotensive group, $(r=0.657)(p=0.039)$, but it was positively correlated with BMI in obese hypertensive group $(r=0.675)$ ( $p=.032$ ). Conclusion: This study suggested that hyperleptinemia may play a role in the pathophysiology of hypertension independently of adiposity and the most correlated parameter to mean $A B P$ among the measured parameters was serum leptin.
\end{abstract}

Keywords: Leptin, Hypertension, Obese. Lipid profile

\section{INTRODUCTION}

Obesity has become one of the most serious health problems in industrialized societies. Weight gain is associated with a high risk of developing cardiovascular and metabolic diseases such as coronary heart disease, hypertension, diabetes \& dyslipidemia ${ }^{(1)}$ Epidemiological studies have demonstrated a close relationship between body mass index
(BMI) and hypertension ${ }^{(1)}$. The association between body weight and blood pressure has been found even in normotensive subjects with normal $\mathrm{BMI}^{(2)}$. Subsequently, clinical studies have demonstrated that weight loss induced by low calorie diet or gastric bypass reduces arterial blood pressure and corrects diabetes and other co morbidities associated with obesity ${ }^{(3)}$.

Adipose tissue was considered exclusively as a body energy store 
without other functions. However, the realizations that adipocytes can produce many hormones including leptin, resistin and adiponectin have led to a view that this tissue is an endocrine secretory organ ${ }^{(4)}$.

Leptin, a peptide hormone discovered to be involved in the regulation of food intake and satiety, as well as in the control of fat accumulation $^{(5)}$. Leptin (from the Greek leptos, meaning thin) is a protein hormone approximately $\sim 16$ $\mathrm{kDa}$ in mass and encoded by the obese (ob) gene ${ }^{(6)}$. Leptin depresses appetite and inhibits fat deposition, particularly in visceral depots and at least part of its effects is mediated by sympathetic nervous system activation $^{(7)}$. Human obesity is associated with elevated plasma leptin levels and resistance to the metabolic effects of the hormone to the extent that high plasma leptin levels are ineffective in reducing fat accumulation $^{(8)}$. In human, the strong interrelation between leptin, BMI and other measures of body fat have made it difficult to investigate the possible influence of that peptide on ABP ${ }^{(9)}$. BMI does not take into account the body fat distribution which appears to confer considerable risk for metabolic abnormalities and cardiovascular disease; hypertension is much more prevalent in persons with central compared with lower body obesity ${ }^{(\mathbf{1 0})}$. The serum concentrations of cholesterol and triglycerides are positively correlated with obesity. ${ }^{(11)}$. Leptin synthesis is induced by hyperglycemia, hyperlipidemia, and a replete fat mass and also leptin suppresses insulin production ${ }^{(\mathbf{1 2})}$. The aim of the present study is to clarify the relationship between serum leptin, blood pressure, body mass index (BMI) and lipid profile, and to explain the possible mechanisms for leptin to produce hypertension in obese males.

\section{SUBJECTS \& METHODS}

\section{Subjects:}

The study was carried out in the Department of Medical Physiology, Faculty of Medicine, Beni-Suef University, Egypt. Cases and control subjects were chosen from those attending the Internal Medicine Outpatient's Clinic in Beni Suef University Hospital and healthy volunteers. They were only male subjects to avoid the multiple variable parameters related to females like adiposity, sex hormones and menopausal state. Participants agreed to participate by written consent. The protocol was based on inclusion and exclusion criteria and is approved by local ethical committee.

The study was done on 40 subjects. They were divided into 2 main groups:

Normotensive group (A) which was subdivided into:

Lean normotensive (LN) subgroup (no. =10) with BMI $<25 \mathrm{Kg} / \mathrm{m}^{2}$

Obese normotensive (ON) subgroup (no. =10) with $\mathrm{BMI}>30 \mathrm{Kg} / \mathrm{m}^{2}$

Hypertensive group (B) which was subdivided into:

Lean hypertensive (LH) subgroup (no. =10) with $\mathrm{BMI}<25 \mathrm{Kg} / \mathrm{m}^{2}$

Obese hypertensive (OH) subgroup (no. =10) with $B M I>30 \mathrm{Kg} / \mathrm{m}^{2}$.

Exclusion criteria

Persons with secondary hypertension and elevated blood sugar levels, patients with other endocrinal 
disorder, infection and inflammation, patients with liver or renal disease and smoker subjects were excluded from the study.

Methods:

Samples collection:

A venous blood sample of $6 \mathrm{ml}$ was withdrawn from each subject while fasting for at least 12 hours. Lipid profile, including serum cholesterol, triglycerides (TGs), low density lipoprotein (LDL), high density lipoprotein (HDL) and very low density lipoprotein (VLDL) were measured after 12 hours overnight fasting by enzymatic colorimetric test. Leptin hormone concentrations were analyzed using Human leptin enzymatic light immunosorbant assay (ELISA) kit from Linco Research (6 Park Drive. St. Charles, Missouri 63304 USA). The analysis of leptin was carried out by using DSX Automated ELISA System from (DYNEX Technologies .Inc.). Lipid parameters were measured by kits supplied by Point Scientific, Inc., Michigan, (U.S.A)

Anthropometric measurements:

Body Mass Index (BMI) was calculated as the weight $(\mathrm{kg})$ divided by the square of the height in meters $(\mathrm{m})^{(\mathbf{1 3})}$. Waist circumference $(\mathrm{cm})$ was taken with a tape measure as the point midway between the costal margin and iliac crest in the mid-axillary line, with the subject standing after full expiration ${ }^{(\mathbf{1 4})}$.

Blood pressure measurements: Blood pressure was measured by using the auscultatory \& palpatory methods using a stethoscope and a sphygmomanometer.

\section{Statistical analysis:}

Analysis of data was done by
IBM computer using Statistical Program for Social Science (SPSS) version 13. Unpaired student t- test was used to compare quantitative variables between two independent groups in parametric data. The normality of distribution of all measured parameters was checked by Kolmogorov - Smirnov test. Analysis of Variance (ANOVA) test was used to collectively indicate the presence of any significant difference between several groups. The test is based on comparing the variance between the groups to the variance within the groups. It is measured as the ratio between these 2 variances (15) followed by Post - hoc LSD analysis to compare various groups with each other. Results were expressed as mean \pm standard deviation (SD). Linear regression analysis was used to find out the effect of different parameters on serum leptin. $\mathrm{P}<0.05$ was considered statistically significant. Pearson correlation coefficient (r) test was used to describe the association between the different studied parameters; $\mathrm{P}<0.05$ was considered statistically significant.

\section{RESULTS}

All subjects completed the study protocol. As shown in table 1, the 4 subgroups were compared for age, BMI, WC, blood pressure, lipid profile and serum leptin. BMI, WC and serum leptin level, were significantly elevated in obese subjects than in lean subjects whether normotensive or hypertensive $(\mathrm{P}<$ 0.001). Serum leptin and mean ABP were significantly higher in hypertensive than in normotensive 
whether obese or lean subjects $(\mathrm{P}<0.001)$. Cholesterol, TG, LDL, and VLDL were significantly higher in the obese subjects, than in the lean only in the normotensive not in the hypertensive subjects. Also these parameters were significantly elevated in hypertensive groups than in normotensive groups whether obese or lean. Among the normotensive subjects, these parameters were higher in the obese group than in the lean group. HDL was significantly higher in the lean normotensive subjects compared to obese normotensive and the lean hypertensive subjects. (Table 1.)

Study of all groups showed that serum leptin was positively correlated with BMI, WC, blood pressure, lipid profile parameters except HDL (Table 2)

In the obese groups $(\mathrm{ON} \& \mathrm{OH}$ together), and lean groups (LN \& LH together), serum leptin was positively correlated with mean $\mathrm{ABP}$ and all lipid profile parameters except HDL to which it was negatively correlated. (Table 3)

Table 4 shows that serum leptin was not significantly correlated with mean ABP either in normotensive (LN \& ON together) or in hypertensive subjects ( $\mathrm{LH} \& \mathrm{OH}$ together). (figure 1), while it was positively correlated with BMI, WC (figure 2) and LDL in both normotensive groups and hypertensive groups It was positively correlated with VLDL in normotensive groups and with Cholesterol (figure 3) and TG (figure 4) in hypertensive groups, while it was negatively correlated with HDL in both groups.
Serum leptin was positively correlated with WC in the obese normotensive group and with BMI in the obese hypertensive group. However, it was negatively correlated with HDL in obese hypertensive group. (Table 5). Using the linear regression analysis, in all studied subjects (LN, LH, ON, OH), revealed that mean ABP was significantly related to serum leptin (Table 6).

Discussion: In the present study there is a significant positive correlation between plasma leptin and body mass index $(\mathrm{r}=0.652, \mathrm{p}<$ $0.001)$ and waist circumference $(\mathrm{r}=$ $0.606, p<0.001$ ) were found in all studied groups. The increase in leptin level in obese persons is explained by dependency of leptin level on the increase in body adiposity. There is a positive correlation between leptin level and measures of increase adiposity (16). Serum leptin correlation with the percentage of body fat, suggests that most obese persons are insensitive to endogenous leptin production (17). Leptin acts in the hypothalamus to decrease food intake and increase thermogenesis, as well as increase sympathetic nerve activity (SNA) to nonthermogenic organs (18). Increasing evidence suggests that these actions can be dissociated in obesity, with resistance to the anorexic and thermogenic effects of leptin (mediated through the arcuate nucleus) but preservation of cardiorenal sympathoactivation (mediated through ventral and dorsal medial hypothalamic nuclei. This phenomenon might explain in part how hyperleptinemia could be accompanied by obesity (partial loss of appetite and metabolic actions of 
leptin) but still contribute to sympathetic over activity and hypertension because of preservation of the sympathetic actions of leptin to some organs involved in blood pressure regulation (18). Serum leptin in our study shows a highly significant positive correlation with the mean ABP $(r=0.612, p<0.001)$ found in all studied groups .

The present study shows higher leptin levels in the obese hypertensive group than in the lean hypertensive group (36.57 \pm 8.47 versus $13.29 \pm 2.84$ $\mathrm{ng} / \mathrm{ml})$ respectively. These results were in agreement with those reported by Uckaya et al. ${ }^{(19)}$, who found a significantly higher leptin level in essential hypertensive patients than in controls as well as a significant correlation between leptin level and blood pressure. However, these results could not be confirmed by Kokot et al. ${ }^{(20)}$, who found no difference in plasma leptin levels between hypertensive patients and normotensive controls.

In another study, Hirose et al. ${ }^{(21)}$ reported a correlation between leptin levels and mean blood pressure after adjustment for age and body mass index. Although, Suter et al. (22), found no association between leptin level and blood pressure in hypertensive men; however they reported a positive relationship on a separate analysis for one women subgroup, as well as normotensive men. In a sample of Japanese men, Masuo et al. (23), revealed a BMI dependant positive relationship between leptin and blood pressure.

According to $\mathbf{H u}$ et al. ${ }^{(24)}$, study in a rural Chinese population sample, the association between blood pressure and leptin was heavily influenced by body fat mass and distribution. Leptin may contribute to end-organ damage in hypertensive individuals such as left ventricular hypertrophy, retinopathy and nephropathy, independent of regulating blood pressure ${ }^{(25)}$. AizawaAbe et al. ${ }^{\text {(26) }}$, found that chronic infusion of leptin and transgenic overexpression of leptin has been shown to increase arterial blood pressure and heart rate. Beltowski et al. ${ }^{(27)}$, have speculated that if patients with hyperleptinemia are resistant to the facilitative effects of leptin on sodium excretion, but are not resistant to the stimulatory effects of leptin on sympathetic and/or reticular activating system (RAS) activity, this would explain why hypertension occurs so often with obesity. Finally, Esler (28) and Sharma et al. ${ }^{(29)}$, reported that in obesity, there is stimulation of sympathetic outflow to the kidneys, evident in increased rate of spillover of noradrenaline into the renal veins and to skeletal muscles vasculature. Also, the high renal sympathetic tone contributes to hypertension development by stimulating renin secretion and through promoting renal tubular reabsorption of sodium. In our study there is a significant positive correlation between leptin and plasma cholesterol $(\mathrm{r}=0.635, \mathrm{p}<0.001)$, triglycerides $(\mathrm{r}=0.581, \mathrm{p}<0.001)$ and LDL $(\mathrm{r}=0.705, \mathrm{p}<0.001)$, and VLDL $(\mathrm{r}=0.497, \mathrm{p}<0.05)$, while there is a significant negative correlation between leptin \& HDL ( $\mathrm{r}$ $=-0.652, p<0.05)$ in all studied groups. Obesity is associated with several deleterious changes in lipid metabolism, including high serum 
concentrations of total cholesterol, LDL, VLDL and TG, and reduction in serum HDL concentration ${ }^{(30)}$. Palou et al, ${ }^{(31)}$ showed that in all age groups, HDL levels were significantly lower in patients who had a high BMI. Hypertriglyceridemia is often associated with reduced levels of HDL suggesting a possible metabolic interaction between these two lipid fractions ${ }^{(32) .}$ The key to this relation may be that the increase in fat deposition in obese individuals is associated with insulin resistance ${ }^{(33)}$, which will lead to increase synthesis of TG-rich lipoproteins in the liver. The increase of TG in lipid particles changes their metabolism. TG-rich HDL particles are hydrolyzed more rapidly causing HDL level to fall ${ }^{(34)}$. The significant association between obesity, BMI and lipid profile in our results is consistent with what was reported by Turki et al ${ }^{(35)}$ who found in their study, that serum leptin correlates positively and strongly with BMI $\quad(r=0.765, P<0.01)$ and also correlates positively with both total cholesterol $(\mathrm{r}=0.394, \quad \mathrm{P}<0.05)$ and LDL $(r=0.366, \mathrm{P}<0.05)$ but correlates negatively with HDL $(\mathrm{r}=$ $0.408, \mathrm{P}<0.05)$. The significant correlations between leptin levels and plasma lipids and between obesity and leptin levels suggest that changes in these parameters play a significant role in determining serum leptin concentrations in obese subjects ${ }^{(36)}$. One of the major mechanisms leading to the development of obesity-induced hypertension appears to be leptinmediated sympathoactivation. Leptin adversely shifts the renal pressure natriuresis curve, leading to relative sodium retention. Although obesity is generally associated with resistance to the anorexic and weight-reducing actions of leptin there is preservation of its sympathoexcitatory and pressor actions. This selective leptin resistance of obesity, coupled with hyperleptinemia, may play a critical role in the cardiovascular complications of obesity. Increased information about leptin and its mechanisms of actions should help the development of safe and effective pharmacological treatments of obesity and obesity-related hypertension ${ }^{(37)}$

Conclusions: From the present results, it was obvious that leptin levels were increased with the increase of the mean ABP in both obese and lean hypertensive patients. Serum leptin, being very high in the obese hypertensive group compared to lean hypertensive group; this may open a new era of the possible effect of hyperleptinemia in the obese hypertensive patients. This is through its relation to the metabolic syndrome being a part of its component or by its influence on the body fat mass, reticular activating system (RAS) and sympathetic nervous system which affect blood pressure in obese patients. There is elevated serum leptin level in obese subjects compared with non-obese ones. In addition, elevated serum leptin level is associated with abnormal lipid profile. Thus circulating leptin levels appear to be one of the best biological markers of obesity and hyperleptinemia is closely associated with several risk factors related to obesity syndrome. 
Table (1): Base line age, body mass index (BMI), waist circumference (WC ) mean arterial blood pressure (MBP), lipid profile \& serum leptin data for lean normotensive, obese normotensive, lean hypertensive, and obese hypertensive subjects

\begin{tabular}{|l|l|l|l|l|}
\hline Parameters & $\begin{array}{l}\text { Lean } \\
\text { Normotensive } \\
\text { LN)( }\end{array}$ & $\begin{array}{l}\text { Obese } \\
\text { Normotensive } \\
(\mathbf{O N})\end{array}$ & $\begin{array}{l}\text { Lean } \\
\text { Hypertensive } \\
(\mathbf{L H})\end{array}$ & $\begin{array}{l}\text { Obese } \\
\text { Hypertensiv } \\
(\mathbf{O H})\end{array}$ \\
\hline AGE $(\mathrm{year})$ & $28.20 \pm 1.98$ & $39 \pm 9.21^{\mathbf{a}}$ & $49.80 \pm 8.18^{\mathbf{b}}$ & $53.30 \pm 6.29^{\mathbf{c}}$ \\
\hline BMI $\left(\mathrm{kg} / \mathrm{m}^{\mathbf{2}}\right)$ & $23.88 \pm 0.80$ & $39.40 \pm 6.19^{\mathbf{a}}$ & $23.49 \pm 0.92$ & $38.58 \pm 6.47^{\mathbf{d}}$ \\
\hline WC $(\mathrm{cm})$ & $90.50 \pm 3.29$ & $121.10 \pm 13.20^{\mathbf{a}}$ & $95.30 \pm 4.32$ & $119.60 \pm 13.90^{\mathbf{d}}$ \\
\hline MBP $(\mathrm{mmHg})$ & $88.47 \pm 5.28$ & $90.13 \pm 5.18$ & $123.64 \pm 6.40^{\mathbf{b}}$ & $126.12 \pm 7.60^{\mathbf{c}}$ \\
\hline CHOL (mg/dl) & $185 \pm 11$ & $203.50 \pm 7.90^{\mathbf{a}}$ & $238.40 \pm 18.60^{\mathbf{b}}$ & $246 \pm 16.60^{\mathbf{c}}$ \\
\hline TG $(\mathrm{mg} / \mathrm{dl})$ & $107.30 \pm 11.90$ & $169.60 \pm 16.40^{\mathbf{a}}$ & $210.40 \pm 12.90^{\mathbf{b}}$ & $206.10 \pm 21.40^{\mathbf{c}}$ \\
\hline HDL $(\mathrm{mg} / \mathrm{dl})$ & $52.90 \pm 6.35$ & $41 \pm 4.05^{\mathbf{a}}$ & $39.30 \pm 3.80^{\mathbf{b}}$ & $36.80 \pm 4.71$ \\
\hline LDL $(\mathrm{mg} / \mathrm{dl})$ & $102.30 \pm 10$ & $122.10 \pm 4.70^{\mathbf{a}}$ & $146.80 \pm 9.40^{\mathbf{b}}$ & $156.70 \pm 7.90^{\mathbf{c}}$ \\
\hline VLDL $(\mathrm{mg} / \mathrm{dl})$ & $29.80 \pm 6.44$ & $40.40 \pm 9.57^{\mathbf{a}}$ & $52.30 \pm 12.10^{\mathbf{b}}$ & $52.50 \pm 13.10^{\mathbf{c}}$ \\
\hline LEPTIN (ng/ml) & $5.94 \pm 1.37$ & $14.91 \pm 3.03^{\mathbf{a}}$ & $13.29 \pm 2.84^{\mathbf{b}}$ & $36.57 \pm 8.47^{\mathbf{c} \mathbf{d}}$ \\
\hline
\end{tabular}

${ }^{\mathbf{a}} \mathbf{P}$ Shows significance between normotensive groups (Lean \& obese).

${ }^{\mathbf{b}} \mathbf{P}$ : Shows significance between lean groups (normotensive \& hypertensive subjects).

${ }^{\mathbf{c}} \mathbf{P}$. Shows significance between obese groups (normotensive \& hypertensive subjects).

${ }^{\mathbf{d}} \mathbf{P}$ : Shows significance between hypertensive groups (obese \& lean subjects).

Table (2): Correlation between serum leptin \& all parameters in all groups (no. $=40$ ).

\begin{tabular}{|l|l|l|}
\hline Parameters & R & P \\
\hline AGE (year) & 0.547 & 0.080 \\
\hline BMI $\left(\mathrm{kg} / \mathrm{m}^{2}\right)$ & 0.652 & $<0.001$ \\
\hline WC $(\mathrm{cm})$ & 0.606 & $<0.001$ \\
\hline MSBP $(\mathrm{mmHg})$ & 0.612 & $<0.001$ \\
\hline CHOL (mg/dl) & 0.635 & $<0.001$ \\
\hline TG $(\mathrm{mg} / \mathrm{dl})$ & 0.581 & $<0.001$ \\
\hline HDL $(\mathrm{mg} / \mathrm{dl})$ & -0.623 & $<0.007$ \\
\hline LDL $(\mathrm{mg} / \mathrm{dl})$ & 0.705 & $<0.001$ \\
\hline VLDL $(\mathrm{mg} / \mathrm{dl})$ & 0.497 & 0.002 \\
\hline
\end{tabular}


Table (3): Correlation between serum leptin \& all parameters in Lean groups $(\mathrm{LN}+\mathrm{LH})($ no. $=20) \&$ Obese groups $(\mathrm{ON}+\mathrm{OH})($ no. $=20)$.

\begin{tabular}{|l|l|l|l|l|}
\hline \multicolumn{3}{|l|}{ lean groups } & \multicolumn{2}{l|}{ Obese groups } \\
\hline Parameters & $\mathrm{r}$ & $\mathrm{P}$ & $\mathrm{r}$ & $\mathrm{P}$ \\
\hline AGE (year) & 0.719 & $<0.001$ & 0.502 & 0.224 \\
\hline BMI $\left(\mathrm{kg} / \mathrm{m}^{2}\right)$ & $0.032-$ & 0.893 & 0.231 & 0.327 \\
\hline WC $(\mathrm{cm})$ & 0.670 & 0.101 & 0.100 & 0.676 \\
\hline MSBP $(\mathrm{mmHg})$ & 0.706 & $<0.001$ & 0.867 & $<0.001$ \\
\hline CHOL $(\mathrm{mg} / \mathrm{dl})$ & 0.823 & $<0.001$ & 0.761 & $<0.001$ \\
\hline TG $(\mathrm{mg} / \mathrm{dl})$ & 0.838 & $<0.001$ & 0.648 & 0.002 \\
\hline HDL $(\mathrm{mg} / \mathrm{dl})$ & $0.745-$ & $<0.001$ & -0.575 & 0.008 \\
\hline LDL $(\mathrm{mg} / \mathrm{dl})$ & 0.878 & $<0.001$ & 0.805 & $<0.001$ \\
\hline VLDL $(\mathrm{mg} / \mathrm{dl})$ & 0.700 & $<0.001$ & 0.530 & 0.016 \\
\hline
\end{tabular}

Table (4): Correlation between serum leptin \& all parameters in normotensive groups $(\mathrm{LN}+\mathrm{ON})($ no. $=20) \&$ Hypertensive groups $(\mathrm{LH}+\mathrm{OH})($ no. $=20)$.

\begin{tabular}{|l|l|l|l|l|}
\hline \multirow{2}{*}{ Parameters } & \multicolumn{2}{l}{ Normotensive groups } & \multicolumn{2}{l|}{ Hypertensive groups } \\
\cline { 2 - 5 } & r & P & r & P \\
\hline AGE (year) & 0.662 & $<0.001$ & 0.016 & 0.945 \\
\hline BMI (kg/m $\left.{ }^{2}\right)$ & 0.900 & $<0.001$ & 0.920 & $<0.001$ \\
\hline WC (cm) & 0.907 & $<0.001$ & 0.768 & $<0.001$ \\
\hline MSBP (mmHg) & 0.246 & 0.296 & 0.200 & 0.398 \\
\hline CHOL (mg/dl) & 0.228 & 0.334 & 0.679 & $<0.001$ \\
\hline TG (mg/dl) & -.0 .082 & 0.731 & 0.823 & $<0.001$ \\
\hline HDL (mg/dl) & $0.655-$ & 0.002 & $0.500-$ & 0.025 \\
\hline LDL (mg/dl) & 0.675 & 0.031 & 0.509 & 0.022 \\
\hline VLDL (mg/dl) & 0.596 & 0.006 & 0.095 & 0.689 \\
\hline
\end{tabular}

Table (5): Correlation between serum leptin levels with all parameters in different subgroups.

\begin{tabular}{|c|c|c|c|c|c|c|c|c|}
\hline \multirow{3}{*}{ Parameters } & \multicolumn{4}{|c|}{ Control "Normotensive" group } & \multicolumn{4}{|c|}{ "Hypertensive" group } \\
\hline & \multicolumn{2}{|c|}{ LN } & \multicolumn{2}{|c|}{ ON } & \multicolumn{2}{|c|}{ LH } & \multicolumn{2}{|l|}{ OH } \\
\hline & $\mathbf{r}$ & $\mathbf{P}$ & $\mathbf{r}$ & $\mathbf{P}$ & $\mathbf{r}$ & $\mathbf{P}$ & $\mathbf{r}$ & $\mathbf{P}$ \\
\hline AGE (year) & $0.436-$ & 0.208 & 0.309 & 0.385 & $0.189-$ & 0.601 & $0.703-$ & 0.123 \\
\hline BMI $\left(\mathrm{kg} / \mathrm{m}^{2}\right)$ & $0.196-$ & 0.587 & 0.595 & 0.069 & 0.593 & 0.071 & 0.675 & $0.032^{*}$ \\
\hline $\mathrm{WC}(\mathrm{cm})$ & 0.254 & 0.0479 & 0.657 & 0.039 & 0.554 & 0.097 & 0.230 & 0.522 \\
\hline MSBP (mmHg) & $0.457-$ & 0.184 & 0.560 & 0.092 & $0.276-$ & 0.441 & 0.195 & 0.589 \\
\hline CHOL (mg/dl) & 0.103 & 0.779 & 0.191 & 0.597 & 0.309 & 0.384 & $0.006-$ & 0.986 \\
\hline $\mathrm{TG}(\mathrm{mg} / \mathrm{dl})$ & $0.325-$ & 0.360 & 0.123 & 0.736 & 0.054 & 0.882 & 0.073 & 0.841 \\
\hline $\mathrm{HDL}(\mathrm{mg} / \mathrm{dl})$ & 0.049 & 0.893 & 0.160 & 0.659 & $0.369-$ & 0.294 & $0.637-$ & * 0.048 \\
\hline LDL (mg/dl) & 0.071 & 0.845 & $0.462-$ & 0.178 & 0.621 & 0.055 & $0.033-$ & 0.927 \\
\hline VLDL (mg/dl) & 0.019 & 0.959 & 0.320 & 0.367 & 0.112 & 0.757 & 0.242 & 0.501 \\
\hline
\end{tabular}


Table (6): Linear regression analysis showing the effects of different parameters on mean ABP.

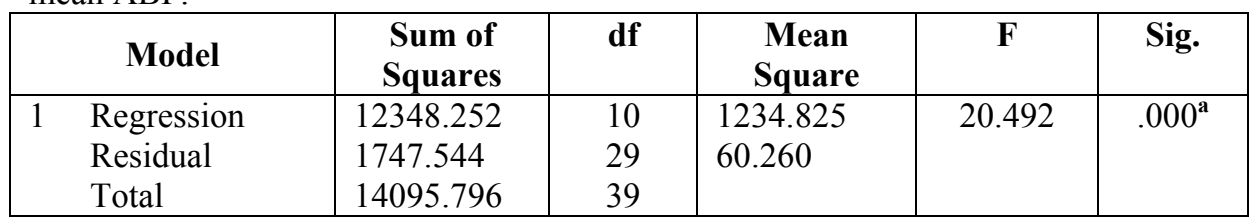

a. Predictors: (Constant), LEPTIN, VLDL, HEIGHT, AGE, WEIGHT, HDL, TG, WC, LDL, BMI

b. Dependent Variable: MBP

\begin{tabular}{|l|r|r|r|r|r|}
\hline \multirow{2}{*}{ Model } & \multicolumn{2}{|c|}{$\begin{array}{c}\text { Unstandardized } \\
\text { Coefficients }\end{array}$} & $\begin{array}{c}\text { Standardized } \\
\text { Coefficients }\end{array}$ & \multicolumn{1}{c|}{ t } & \multirow{2}{*}{ Sig. } \\
\cline { 2 - 5 } & \multicolumn{1}{|c|}{ B } & \multicolumn{1}{c|}{ S.E. } & \multicolumn{1}{c|}{ Beta } & & \\
\hline 1 (Constant) & -390.522 & 186.116 & & -2.323 & .027 \\
AGE & .505 & .192 & .319 & 2.632 & .013 \\
BMI & 4.964 & 1.976 & 2.321 & 2.512 & .018 \\
WC & .416 & .182 & .372 & 2.283 & .030 \\
TG & $3.567 \mathrm{E}-02$ & .063 & .084 & 0.562 & .578 \\
HDL & .191 & .291 & 0.78 & .654 & .518 \\
LDL & .235 & .138 & .283 & 1.703 & .099 \\
VLDL & .167 & .136 & .123 & 1.231 & .228 \\
LEPTIN & .708 & .200 & .463 & 3.531 & .001 \\
\hline
\end{tabular}

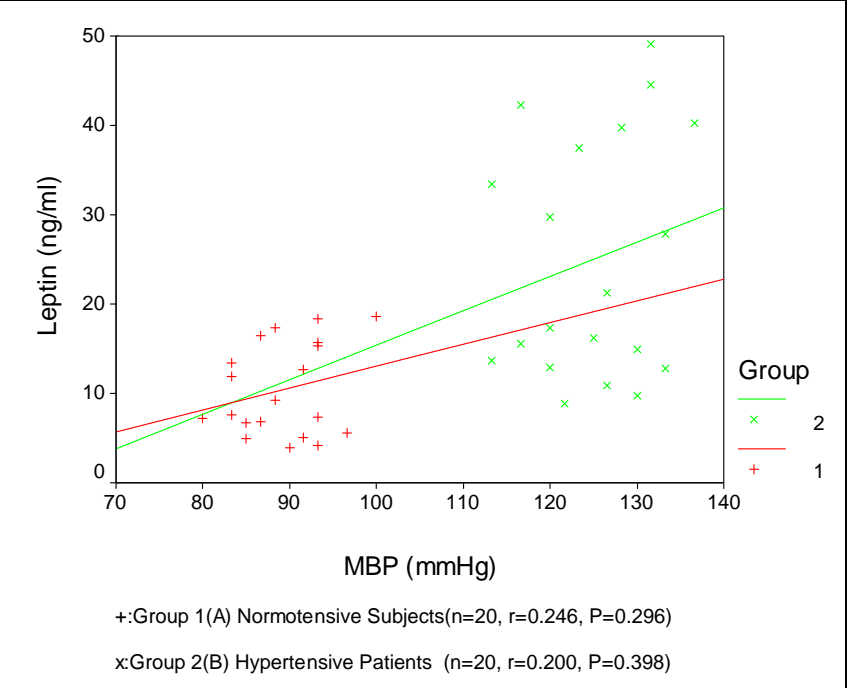

Fig.(1): Correlation between serum leptin and mean Arterial Blood Pressure (mean ABP) in A \& B groups. 


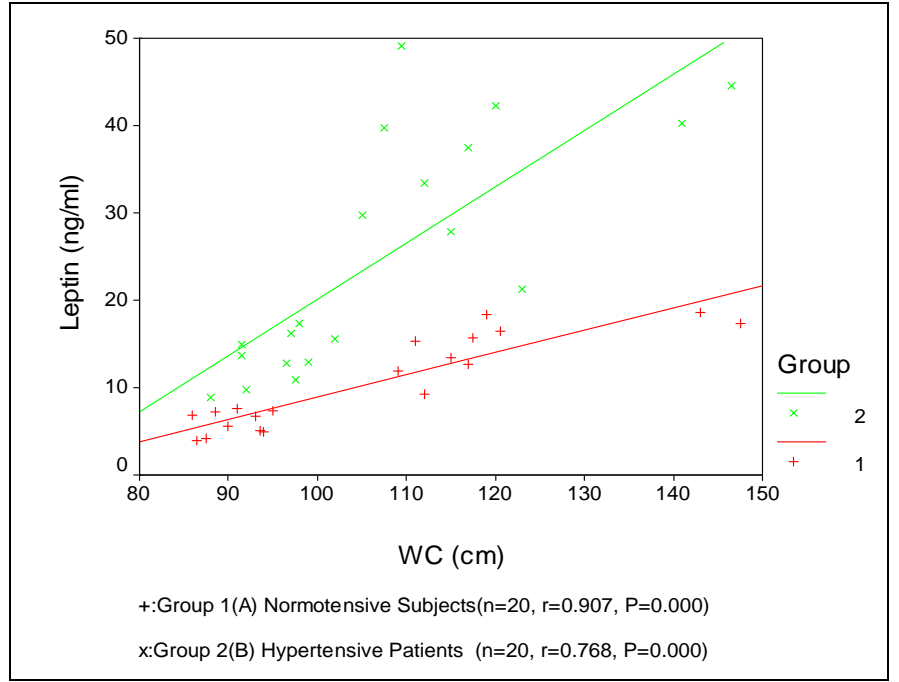

Fig.(2): Correlation between serum leptin and W.C. in A \& B groups

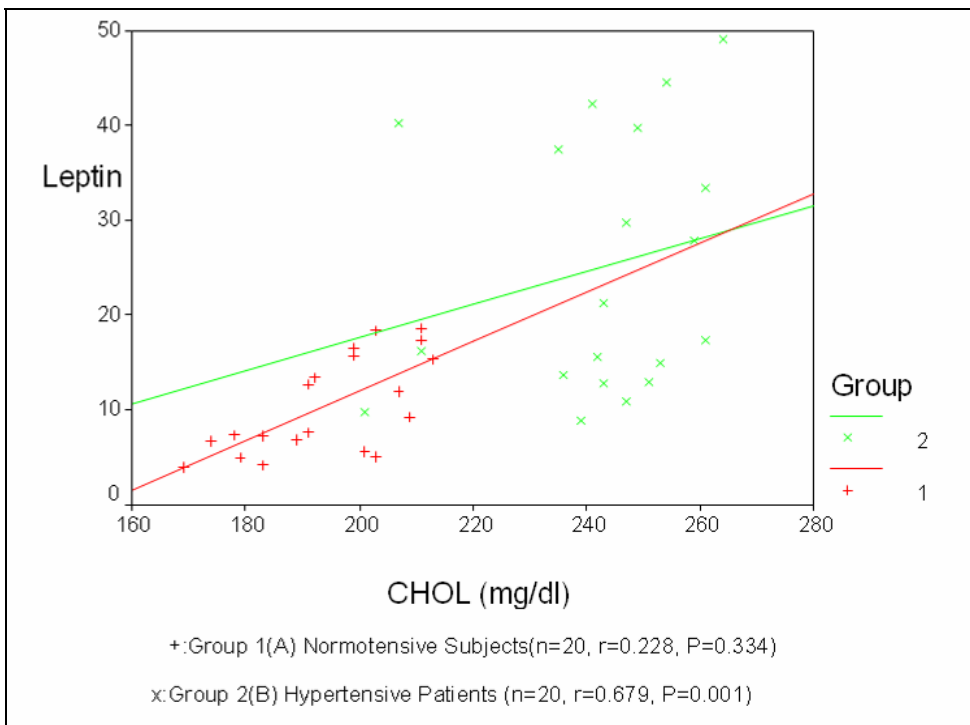

Fig.(3): Correlation between serum leptin and total cholesterol in A \& B groups 


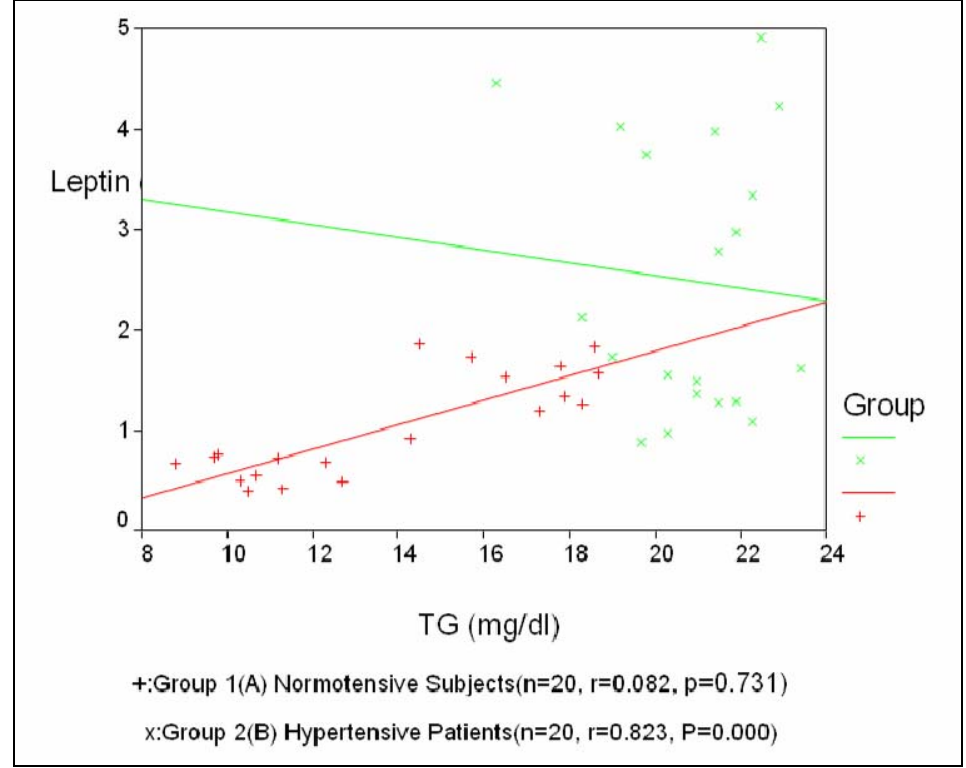

Fig.(4): Correlation between serum leptin and $\mathrm{TG}_{\mathrm{s}}$ in $\mathrm{A} \& \mathrm{~B}$ groups

\section{REFERENCES}

1. Kopelman PG. (2000): Obesity as a medical problem. Nature; 404: 635-643.

2. Mikhail $N$ and Tuck ML (2000): Epidemiological and clinical aspects of obesity related hypertension. J. Clin. Hypertens;2: 41-45.

3. Richards RJ, Thakur V \& Reisin E (1996): Obesity related hypertension: its physiological basis and pharmacological approaches to its treatment. $J$. Hum Hypertens;10: 922-928.

4. Bradley RL, Cleveland KA \& Cheatham B. (2001): The adipocyte as a secretory organ: mechanisms of vesicle transport and secretory pathways. Recent Prog Horm Res;56: 329-358.
5. Friedman JM. (2000): Obesity in the millennium. Nature;404: 632-34.

6. Haynes WG, Morgan DA, Djalali A et al. (1999): Interactions between the melanocortin system and leptin in control of sympathetic nerve traffic. Hypertension;33: 542547.

7. Narkiewicz K, Somers VK, Mos L et al. (1999): An independent relationship between plasma leptin and heart rate in untreated patients with essential hypertension. J. Hypertens;17: 245-249.

8. Kokot F, Adamczak M, Wiecek A et al. (1999): Does leptin play a role in the pathogenesis of essential hypertension? Kidney Blood Press Res;22: 154-160. 
9. Kissebah AH and Krakower GR. (1994): Regional adiposity and morbidity. Physiol. Rev;74: 761-811.

10. Chow VT and Phoon MC. (2003): Measurement of serum leptin concentrations in university undergraduates by comparative ELISA reveals correlation with BMI and Sex. Adv. Physiol. Educ;27 (1-4): 70-77.

11. Young DS and Bermes EW. (2006). Preanalytical Variables\& Biological Variation. In: Burtis CA, Ashwood ER, Bruns DE. Tietz textbook of Clinical Chemistry, $4^{\text {th }}$ ed. vol 2. Hsevier Saunders,; 17,449-473.

12. Herbert PN. (2001). Eating Disorders. In: Andreoli TE, Carpenter ChJ, Griggs RC, Loscalzo J. Cecil Essentials of Medicine, $5^{\text {th }}$ ed. W.B. Saunders Company;59,515-521.

13. Laquatra (2000): Nutrition for Weight management. In Food, Nutrition and diet therapy; 10th edition, Ch.23, P.485-513.

14. Lean ME, Han TS \& Morrison CE. (1995): Waist circumference as a measure for indicating need for weight management. Bri. Med. J.;311: 158-161.

15. Knapp RG. and Miller MC. (1992): Tests of statistical significance: Analysis of variance in clinical epidemiology and biostatistics, Williams and Wilkins, Baltimore, p.293.

16. 16 . Considine RV and Caro JF. (1996): Leptin in humans: current progress and Future directions. Clinical Chemistry;42 (6): 843-844.

17. Sinha MK and Caro JF. (1998):
Clinical aspects of leptin. Vit. Horm.;54: 1-30.

18. Correia $M$ and Haynes $W G$. (2008): Does selective leptin resistance cause obesity-related hypertension? Rev Bras Hipertens vol.15(4):189-194

19. Uckaya G, Ozata M, Sonmez A et al. (2000): Is leptin associated with hypertensive retinopathy? $J$. Clin. Endocrinol. Metab;85: 683687.

20. Kokot F, Wiecek A, Mesjasz J et al. (1998): Influence of longterm recombinant human erythropoietin (rHuEpo) therapy on plasma leptin and neuropeptide $\mathrm{Y}$ concentration in haemodialysed uraemic patients. Nephrol. Dial. Transplant;13: 1200-1205.

21. Hirose H, Saito I, Tsujioka $M$ et al. (1998): The obese gene product; leptin: possible role in obesity-related hypertension in adolescents. J. Hypertens;16: 2007-2012.

22. Suter PM, Locher R, Hasler E et al. (1998): Is there a role for the ob gene product; leptin in essential hypertension? Am. J. Hypertens; Nov. 11 (II pt. I): 1305-11.

23. Masuo K, Mikami H, Ogihara T et al. (2001): Weight reduction and pharmacologic treatment in obese hypertensives. Am. Hypertens; 14: 530-538.

24. Hu FB, Chen $C$ \& Wang $B$. (2001): Leptin concentrations in relation to overall adiposity, fat distribution and blood pressure in a rural Chinese population. Int. J. Obes. Relat. Metab. Disord;25: 121-125. 
25. Ukkola O, Tremblay A, Sun G et al. (2001): Genetic variation at the uncoupling protein $1,2 \& 3$ Locus and the response to longterm over feeding. Europ. J. of Clin. Nut;55: 1008-1015.

26. Aizawa-Abe $M$, Ogawa $Y$, Masuzaki $H$ et al. (2000): Pathophysiological role of leptin in obesity-related hypertension. $J$. Clin. Invest.;105: 1243-1252.

27. Beltowski J, JamrozWis'niewska A, Borkowska E et al. (2005): Antioxidant treatment normalizes renal Na,K-ATPase activity in leptin treated rats. Pharmacol Rep.;57: 219-228.

28. Esler M. (2000): The sympathetic system and hypertension. Am. J. Hypertens;13: 99s-105s.

29. Sharma AM, Schorr $U$ and Distler A. (1993): Insulin resistance in young salt-sensitive normotensive subjects. Hypertension;21: 273-279.

30. Grundy SM, Barnett JP. (1990) - Metabolic and health complications of obesity. Dis Mon;36,641.

31. Palou A , Serra F, Bonet et al. (2000) ."Obesty: molecular bases of a multifctorial problem". Eur J Nutr;39,127-144.
32. Rosenson RS. (2007) . Screening Guidelines for dyslipidemia. J Up To Date $; 15,1$.

33. Ginsberg HN, Stalenhoef AF. (2003) . The metabolic syndrome: targeting dyslipidemia to reduce coronary risk. J Cadiovasc Risk;10,121-128.

34. Carr MC, Brunzell JD. (2004) .Abdominal obesity and dyslipidemia in the metabolic syndrome: importance of type 2 diabetes and familial combined hyperlipidemia in coronary artery disease risk. J Clin Endocrinol Metab;89,2601-2607.

35. Turki K M, Alosami $M$ H and Abdul-Qahar Z H (2009) :The Effect of Obesity on Serum Leptin and Lipid Profile. The Iraqi Postgraduate Medical Journal vol.1, no. 1,27-32

36. Cordero-MacIntyre ZR, Metghalchi S, Rosen J, et al. (2004) .Impact of Weight Loss on Serum Leptin in Obese Postmenopausal Women. J Appl Res; 4,60-67.

37. Haynes W G.(2005): Role of leptin in obesity-related hypertension . Exp Physiol 90.5 pp 683-688 . 


\section{العلاقة بين مستوى هرمون الليبتن في الام و ضغط الام في الأكور البدينة والغير بلدينة في الأنم

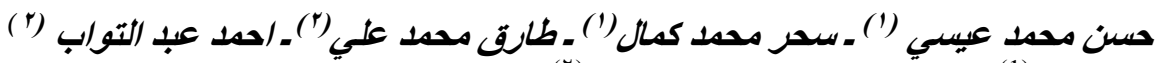

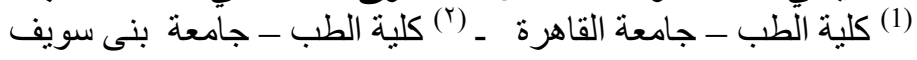

الهرف من البحث: تم تصميم هذه الدر اسة بهدف نوضيح العلاقة بين مستوى اللبتين في الدم و ارتفاع ضـغط الدام

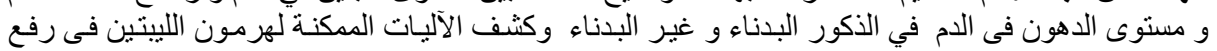

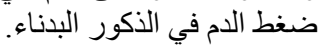

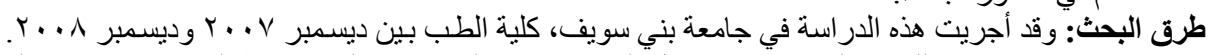

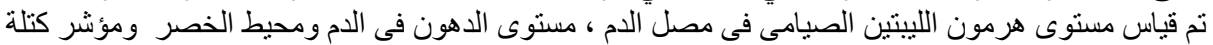

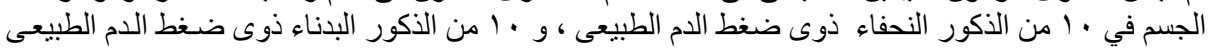

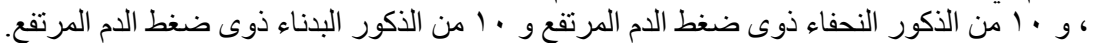

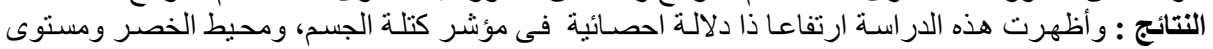

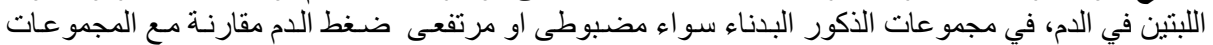

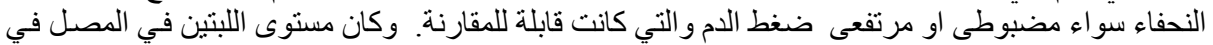

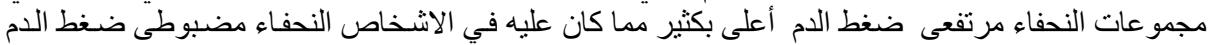

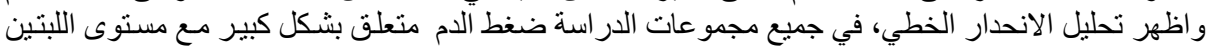

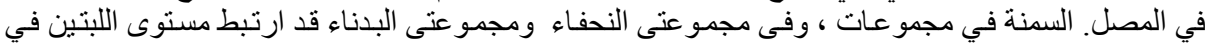

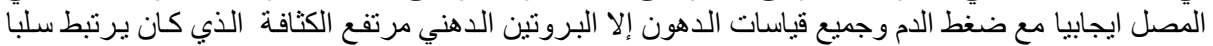

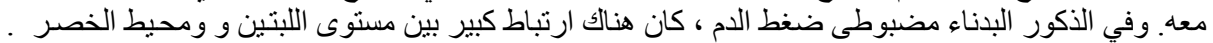
بينما في مجمو عة الذكور البدناء ذوى ضغط اللدم المرتفع ، فقد ارتبط مستوى اللبتين بشكل إيجابي مـع مؤشر

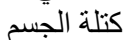

الخلاصة : من النتائج الحالية، اقترحت هذه الدر اسـة ان ارتفاع مستوى اللبتين قد يلعب دور البـا في الفيزيولوجيا

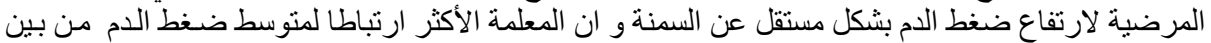

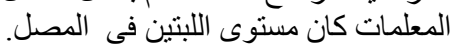

